Article (refereed) - postprint

Dixon, Harry; Hannaford, Jamie; Fry, Matthew J. 2013. The effective management of national hydrometric data: experiences from the United Kingdom.

(C) 2013 IAHS Press

This version available http://nora.nerc.ac.uk/500481/

NERC has developed NORA to enable users to access research outputs wholly or partially funded by NERC. Copyright and other rights for material on this site are retained by the rights owners. Users should read the terms and conditions of use of this material at http://nora.nerc.ac.uk/policies.html\#access

This is an Author's Accepted Manuscript of an article published in Hydrological Sciences Journal (2013), 58(7). 1383-1399, copyright IAHS Press, available online at:

http://www.tandfonline.com/10.1080/02626667.2013.787486 


\title{
The effective management of national hydrometric data - experiences from the United Kingdom
}

\author{
Harry Dixon*, Jamie Hannaford, Matthew J. Fry \\ *Corresponding author \\ Centre for Ecology and Hydrology, Maclean Building, Crowmarsh Gifford, Wallingford, OX10 8BB, United \\ Kingdom \\ harr@ceh.ac.uk
}

\begin{abstract}
Access to hydrometric information underpins many areas of effective water management. This paper explores the operational practices of one National Hydrological Information Service, the UK National River Flow Archive, in collating, managing and providing access to river flow data. An information lifecycle approach to hydrometric data management is advocated, with the paper detailing current UK procedures in the areas of: monitoring network design and development; data sensing and recording; validation and archival; synthesis and analysis and, data dissemination. The methods and policies outlined in this paper are widely transferable to other hydrological data archives around the world.
\end{abstract}

Keywords hydrometric information, data management, monitoring, gauging station networks, river flow data, hydrometry

La gestion efficace des données hydrométriques nationales - d'après l'expérience du Royaume Uni

Résumé - L'accès à l'information hydrométrique forme la base de nombreux domaines liés à une gestion efficace de l'eau. Cet article explore les pratiques opérationnelles d'un Service National d'Informations Hydrologiques, le UK National River Flow Archive (Archives nationales des écoulement en rivière du Royaume Uni), au niveau de la collation, de la gestion et de l'accès aux données d'écoulement en rivière. Pour la gestion des données hydrométriques, une approche basée sur le cycle de vie de l’information est préconisée. Cet article détaille les procédures actuelles en vigueur au Royaume Uni dans les domaines suivants: conception et création de réseaux de collecte, captage et enregistrement des données, validation et archivage, synthèse et analyse, et enfin, dissémination des données. Les méthodes et principes décrits dans cet article sont en grande partie transférables à d'autres archives de données hydrologiques à travers le monde.

mots-clés - l’information hydrométrique, gestion des données, surveillance, réseaux de stations de jaugeage, aux données d’écoulement en rivière, hydrométrie

\section{INTRODUCTION}

The availability of records of river flow is vital to developing our understanding of the hydrological cycle. Monitoring of the flow at discrete points on a river system allows hydrologists to quantify the integrated output of all hydrological processes acting upon a catchment, and thereby underpins effective water management across areas such as flood risk estimation, water resources management, hydro-ecological assessment and hydropower generation.

Recognition of the fundamental importance of hydrometric monitoring in enabling informed operational and policy decisions across many areas of society led to a growth in river gauging networks throughout the world in the second half of the $20^{\text {th }}$ Century (Rodda 1998). Developments in hydrometry and the widespread adoption of digital recording, coupled with 
the growth of information technologies, in particular the development of the internet, have provided the tools for more efficient hydrometric data collection and exchange. At the same time, escalating analytical capabilities and a heightened awareness of the changing environment has further increased the demand for access to such information.

In spite of recent developments however, the availability of hydrometric information continues to constrain research and operational hydrology across the globe. The Third World Water Development Report concluded that, “worldwide, water observation networks provide incomplete and incompatible data on water quantity and quality for managing water resources and predicting future needs" (Grabs 2009, p.226). Globally, funding constraints and changing governmental priorities have resulted in a decline in some river gauging station networks (Mishra and Coulibaly 2009, Hannah et al. 2010), whilst concerns about misuse of data, commercial drivers, political sensitivities about transboundary resources and an overarching lack of understanding about the value of river flow information limit the exchange of the hydrological data that is collected (Grabbs 2009, Viglione et al. 2010). The result is that many operational water managers lack adequate information to inform decision making (World Water Council 2009) and large-scale research data archives are insufficiently populated (Nelson 2009, Hannah et al. 2010) - problems which are ever more acute in the light of increasing global concerns surrounding hydrological variability. Although there is a pressing requirement to address the inadequacies in river gauging networks and improve hydrometric practices to ensure flows are accurately recorded, perhaps as acute is the need to optimise data management and dissemination practices to maximise the benefits of existing monitoring. At this time of both enhanced demand for river flow data and increasing financial pressure on the organisations tasked with maintaining networks, methods for maximising the societal benefits of hydrometric information are of crucial importance.

While the need for global agreements on environmental information sharing and maintenance of large-scale, international data archives and monitoring networks (e.g. Hannah et al. 2010, Whitfield et al. 2012) is widely acknowledged, the funding and management of most hydrometric data collection remains at a national (or sub-national) scale and thus, National Hydrometric Information Services (NHIS) remain one of the most appropriate mechanisms for providing enduring access to comprehensive, high quality river flow information. Many of the barriers to the flow of hydrometric information exist at a local scale and, in the face of declining resources, the optimisation of national data systems is vital to ensuring efficiency and maximising the information gleaned from monitoring networks. Improvements to national procedures for the management and dissemination of river flow information are therefore a necessary first step to facilitating widespread global data sharing.

This paper presents experiences from one National Hydrometric Information Service, the United Kingdom National River Flow Archive (NRFA), in managing national scale river flow data. The aim of the paper is to illustrate the operational practices that are employed by the NRFA in the acquisition, management and analysis of river flow data from the UK gauging station network, including some novel approaches to information management which could potentially find application in other hydrometric networks around the world. The potential benefits of improved exchange of scientific-technical expertise between NHIS have 
been acknowledged by international bodies such as the World Meteorological Organization (WMO) and it is hoped that this example could also encourage dialogue between national services.

\section{UK HYDROMETRIC MONITORING}

In a global context the UK hydrometric gauging station network is very dense - largely a response to both the high drainage density and the marked climatological, geological, land use and water utilisation diversity of the British Isles (Marsh 2002). Although considerable spatial variations exists across the country, in global terms watercourses are generally short, shallow and in places subject to considerable artificial disturbance. A total of around 1250 primary gauging stations are currently operated by three major publically funded measurement agencies (Figure 1a). Partially as a result of a well-developed rain gauge network, hydrometric monitoring remained sparse in the UK until the 1960s, when increased water resource demands and legislative changes led to a rapid expansion of the gauging station network (Figure 1b). Consequently the national hydrometric database currently holds around 50000 station-years of flow data, with an average record length of 34 years per station.

The UK NRFA is a publically funded national focal centre for hydrometric information storage, analysis and dissemination. Like many National Hydrometric Information Services around the world, the NRFA provides access to river flow data and associated information, as well as knowledge, advice and decision support on a range of national hydrological issues (WMO 2006). Originally setup in 1935, the national archive's current objectives include: provision of a coherent UK-wide database of daily river flow data openly accessible to all users; meeting national and international obligations for hydrometric data dissemination and exchange; assessment and reporting of national and regional water resources; monitoring of hydrological variability; and the raising of public awareness and understanding of waterrelated issues (Marsh 2002). While the organisational structures are often different, similar drivers provide the current focus for other National Hydrometric Information Services (for example, the United States Geological Survey (USGS) National Streamflow Information Program (Norris 2009) and the Australian Bureau of Meteorology Water Information Program (BoM 2010)).

Under the UK's distributed model for delivering hydrological services, daily mean river flow data, and associated metadata, are provided to the NRFA by regional hydrometric measuring authorities (primarily: the England and Wales Environment Agency; Scottish Environment Protection Agency; and the Rivers Agency, Northern Ireland) who have responsibility for network installation and upkeep, data collection, data processing and initial data validation. The data then undergo secondary validation by the NRFA before being added to the national archive for long-term storage and dissemination. While the archive exists in a separate organisational structure to the major national and regional hydrometric measuring authorities, the NRFA is delivered through close collaboration between data providers, the scientific research community, other data users and national government. The archive serves a wide user community incorporating water management professionals, scientific researchers, educational users, the media, national government bodies and international organisations. 
In the context of this paper the term hydrometric data is used to primarily refer to river discharge records as, within the UK, the monitoring and data archival for other hydrological variables (e.g. precipitation and groundwater) are primarily delivered through different organisational structures. The majority of UK hydrometric monitoring is conducted at a 15minute time interval. While these high resolution series form the basis of regional hydrometric measuring authority's operational databases, river discharge records are archived on the NRFA at a daily time step (as mean flow for the 09:00-09:00 UK water day). Many of the policies, processes and methologies described could however be readily transferable to other environmental variables and/or temporal resolution data.

\section{THE HYDROMETRIC INFORMATION LIFECYCLE}

The management of hydrometric data can be considered using a data lifecycle approach (Figure 2), whereby the different processes of data sensing, manipulation and use are stages in the development and flow of information (Marsh 2002). By considering the production, management, dissemination and analysis of hydrometric data as one complete system, the artificial barriers between 'data providers' and 'data users' can be reduced and improvements made to the efficiency of the whole system. The analysis of information, and ultimately the associated decision making, provide end points in the hydrological information lifecycle. Marsh (2002) highlighted that in an effective system these later stages of information use should also provide continuous feedback influencing the overall design and structure of the system. As a result, it is more useful to consider the system as a continuous cycle rather than a linear process. National Hydrometric Information Services play a vital role in development of hydrometric information, by both fulfilling functions within the cycle and also acting as a key feedback loop between data users and those responsible for data collection. The NRFA maintains involvement in all stages of the information lifecycle, interacting with data providers, analysts and policy-makers to maximise the utility of the national datasets. This paper will consider the key stages in the lifecycle, from monitoring network design and data measurement to information dissemination and reporting, detailing key NRFA involvement in each.

\section{Monitoring Network Design and Development}

Globally, surface water monitoring networks have been designed, and subsequently evolved, to meet a range of needs, most commonly water resources assessment and hydrological hazard mitigation (WMO 2008). The assessment and development of monitoring networks is often driven by operational data needs for water management (e.g. monitoring of water abstractions, flood warning, ecological status regulation) and controlled by short- to mediumterm economic constraints. Within the UK the national archive advocates the consideration of longer-term national and international strategic data needs as key drivers for network development. For example, the maintenance of strategic networks of gauging stations suitable for the identification and interpretation of long-term hydrological change, or for supporting the development of scientific methods for prediction of flow in ungauged basins, are key capabilities of a national hydrometric network and should be considered alongside operational needs (Marsh 2002). 
In this context, subsets of the UK gauging station network have been identified to meet a number of key national strategic needs. Since its initial designation, the network of UK 'Benchmark' catchments (Bradford and Marsh 2003) have assumed particular importance in strengthening national capabilities in assessing climatically driven changes in river flow patterns. The network of around 130 gauging stations across the UK are designated based on hydrometric performance, the degree of artificial influence to the flow regime, homogeneity of the time series and length of flow record (Figure 3a). The primary role of the network is in allowing researchers to discern climate-driven responses from other, more direct anthropogenic influences (e.g. abstractions, effluent discharges, reservoirs). As such, the network is finding increasingly wide application in studies which require a near-natural flow response, e.g. trend analysis studies seeking to characterise climate-driven hydrological change (Hannaford and Marsh 2006, 2008). Benchmark catchments are also used to promote the synergistic benefits of integrated environmental monitoring, i.e. focusing monitoring resources on basins where other parts of the hydrological cycle (e.g. rainfall, groundwater, soil moisture) are well monitored, enabling improved understanding of catchment processes.

The UK Benchmark network is also contributing to several wider international initiatives. On a European scale, the network has been integrated with near-natural catchments from 10 other European countries as part of a pan-European trend analysis (Stahl et al. 2010). Outside Europe, a number of similar sub-networks of national surface water monitoring programmes exist for the detection of climatically driven hydrological change - for example the Canadian Reference Hydrometric Basin Network (RHBN: Harvey et al. 1999) and the USGS Hydroclimatic Data Network (HCDN: Slack and Landwehr 1992). Recently, an initiative has begun to integrate national "reference" networks into a global network of near-natural catchments, with the UK benchmark network (along with the RHBN and the HCDN) being one of the exemplar networks which are at the vanguard of this initiative (Burn et al. 2012, Whitfield et al. 2012).

Other sub-network initiatives can be developed to meet other requirements, such as designation of gauging stations with good hydrometric performance at high flows for use in flood estimation methodologies (e.g. Institute of Hydrology 1999) (Figure 3c). The use of high flow data in flood risk management, for example in the design of hydraulic structures and implementation of planning controls, represents one of the key national benefits of the hydrometric monitoring network. While the specific strategic needs will vary internationally, the role of National Hydrometric Information Services in designating such sub-networks and promoting their importance is central to ensuring that the evolution of monitoring reflects both the long-term strategic benefits of existing, or potential future, gauging stations as well as immediate operational needs.

Within the UK, as in many areas of the world where surface water monitoring networks are well established, there is an ongoing need to assess the current utility of the network in order to optimise the information it delivers. Such assessments are often a necessary response to historical reductions in network density and the pressure to maximise the cost-benefit of publically funded monitoring investment (Mishra and Coulibaly 2009). The NRFA has therefore been pro-active in developing tools for scientifically-informed network appraisal. 
A particular focus has been in assessing the utility of the network for regionalisation, i.e. the prediction of hydrological characteristics at ungauged locations, via extrapolation in space from locations where gauged data is available. This is one of the key challenges in contemporary hydrology, and has been at the forefront of the Prediction in Ungauged Basins (PUB decade, 2003 - 2012) initiative (e.g. Franks et al. 2005). Data users are often concerned with the degree to which a gauged catchment has similar characteristics to a wider reference area, or identifying those stations suitable for use with regionalisation techniques, which frequently form the basis of methodologies for assessing flow regimes at ungauged sites. To this end the NRFA has led development of indices such as the 'Representative Catchment Index’ (RCI) (Laizé 2004) which uses sophisticated GIS techniques to assesses how representative a gauged catchment is of a wider region of interest (e.g: an administrative region; a Water Framework Directive River Basin Districts; physiographic area such as "upland UK") in terms of land-use, elevation and geology. Another decision-support tool developed by the NRFA is the 'Catchment Utility Index' (CUI) method (Laizé et al. 2008), which provides an assessment of a catchment's value in relation to regionalisation and capitalises on procedures developed for the Flood Estimation Handbook (Institute of Hydrology 1999), a UK industry standard used for flood frequency estimation. Recently these catchment assessment techniques have been combined with others measures of catchment utility and gauging station performance to develop a new methodology for optimization of networks for regionalisation (Hannaford et al. in press), which was then applied to the England and Wales gauging station network as part of a review undertaken for the Environment Agency (Davis et al. 2010).

National Hydrometric Information Services are uniquely placed to develop such methodologies and conduct end-user focused assessments of hydrometric networks at national or international scales. NHIS are able to ensure scientific needs (such as the requirement to maintain stations suitable to inclusion in 'Benchmark' networks and the vital importance of preserving stations with long observational records) are considered in the early stages of the information lifecycle. This role is particularly important in the current climate of economic constraints; against a backdrop of decreasing resources available for monitoring, NHIS' are well placed to ensure that key national strategic objectives are safeguarded when networks come under financial pressure.

\section{Data Sensing and Recording}

Responsibility for operation and maintenance of hydrometric networks is frequently devolved to organisations at a regional or sub-regional level who then cooperate to deliver data under a common framework. National Hydrometric Information Services are able to ensure consistency in data collection and processing methods across different measuring authorities and promote best practice. In the UK, operational procedures in relation to hydrometry and initial data processing (including station design, flow gauging and rating development) are generally set by the individual measuring authorities, who have primary responsibility for operation and maintenance of surface water monitoring networks. The diverse nature of UK hydrology means that each regional measuring authority operates gauging stations which employ a range of different hydrometric techniques. Nationally around $55 \%$ of stations are 
purpose build gauging structures (e.g. weirs, flumes), 35\% are rated open channel sections and 6\% use ultrasonic or electromagnetic flow measurement methods (see Marsh and Hannaford 2008 for more detail of the UK network composition). In light of this diversity, to ensure consistency across the network, operational procedures are developed in line with appropriate national (British Standards Institution - BSi) and international (e.g. European Committee for Standardization - CEN, International Organization for Standardization - ISO) standards (Herschy 2009) and involvement in the development of standards represents one route to influencing best practice. The NRFA acts as a central source of expertise for measuring authorities in regard to all areas of hydrometry, especially those related to the processing, management and quality control of data.

National Hydrometric Information Services are constantly required to maintain a balance of knowledge between a national scale overview and regional/sub-region hydrometric awareness. To data collectors a NHIS can provide information and feedback from information end-users at national and international levels, while to data analysts it is important that the service supports the transfer of detailed local level information regarding the hydrometry and catchment characteristics of specific gauging stations. In the UK, the maintenance of local knowledge is facilitated through a network of NHIS staff who are each given specific responsibility of a geographically-defined subset of the network. These designated regional representatives build up important local network knowledge (for example, on current performance issues affecting particular stations) through involvement in data quality control, the production of user guidance information and maintenance of the detailed hydrometric metadata on the national database. Regular liaison is maintained between regional measuring authorities and the national archive through a combination of field site visits, written guidance, collaborative projects and reporting, in order to maintain strong working relationships, provide feedback and influence day-to-day working practice.

In order to maximise the sharing of local information between the hydrometric measuring authorities and the national archive, the NRFA has developed a 'Hydrometric Data Audit' (HDA) framework. The HDA programme, started in 2006, aims to provide assessments of the overall quality and availability of hydrometric information available from part of the gauging network. Applied to geographical sub-regions of the UK, the HDAs focus on the more strategically valuable components of the network, assessing the current status of the hydrometric monitoring programme and identifying ways of maximising the utility of the data it provides. The audits include a regional network appraisal considering the representativeness and utility of the gauging station network, using the previously mentioned RCI and CUI methods. Such assessments determine how well the local network contributes to the overall strategic requirements for the national network. For example, an HDA may identify a gauging station which at a regional level is thought to be of little utility in operational water resources or flood management but, when considered in a national context, could form an important part of the aforementioned UK Benchmark network due to its relatively undisturbed catchment.

Other aspects of the audits capitalise on existing quality control mechanisms and are aimed at assessing and improving data completeness, quality and homogeneity. By viewing issues 
such as data completeness in a longer term context, the initiative can identify underlying patterns of missing data, prompting reviews of operational practices and efforts to improve records through the use of backup data or flow estimation. Perhaps most importantly, the framework provides a forum for discussing priority hydrometric topics (e.g. the credibility of extreme flow data) and addressing station specific issues (e.g. current maintenance issues and proposed changes to measurement methods). New hydrometric technologies provide the opportunity to enhance data quality (for example, improved high flow ratings as a result of using Acoustic Doppler Current Profilers (ADCPs) to capture floodplain flow). HDAs provide an opportunity to consider how such developments would improve the utility of individual flow records to users and to discuss priority stations for employing such technologies.

The programme is a collaborative venture between the NRFA and the UK hydrometric measuring authorities which not only maximises the utility of the national archived hydrometric data but also, over time, enhances the strategic capability of the gauging network by providing feedback on large-scale needs and priorities. Initiatives such as the HDA programme represent practical areas in which NHIS can promote feedback and enhance linkages in the hydrometric data information cycle.

\section{Data Validation and Archival Storage}

The quality control and long-term archiving of hydrometric data represent a central function of National Hydrometric Information Services. Under an organisational system where the core responsibility for quality control of river flow data rests with distributed data providers, independent national-level appraisal of data can provide significant benefits to the final information product. This is particularly true where the national assessments take a userfocused approach to improving the information content of datasets, placing strong emphasis on maximising the final utility of data - for example through efforts to improve data completeness, provide user guidance and promote network stability.

With the aim of controlling the process of data transfer between organisations and coordinating data validation and improvements, a Service Level Agreement (SLA) was developed in the UK between the national archive and hydrometric measuring authorities. The agreement, which covers the annual transfer and subsequent process of validation of river flow data, is designed to maintain and improve the utility, continuity and fitness-forpurpose of nationally archived data. Through parallel development with network assessment initiatives, the SLA promotes long-term stability in the core national hydrometric network, focusing data validation and dissemination activities on the more strategically valuable gauging stations. Around 700 stations, roughly $60 \%$ of the currently operational flow stations in the UK, are designated under the SLA (Figure 3b). A similar aim of developing a core, stable, network of gauging stations is central to the United States National Streamflow Information Programme, developed in response to concerns in the 1990s about declining hydrometric networks (Norris 2009).

The SLA provides a framework to manage the annual data transfer to the NHIS and its subsequent validation (Figure 4). Under the UK system, data are transferred from on-site 
gauging station data-loggers to operational databases by regional measuring authorities (largely via automated telemetry systems). Following initial automated and manual quality control by local hydrometric experts, data is transmitted to the NRFA. River flow data submitted by measuring authorities are loaded and validated by NRFA staff using a suite of in-house developed software applications. Un-validated data are kept separate from the main national archive until a series of manual and automated checks have been conducted. This process of data validation is conducted by the experienced NRFA regional representatives, as the diverse hydrological environments found in the UK, coupled with significant anthropogenic disturbance to flow regimes, implies that hydrograph appraisal undertaken by personnel familiar with the expected flow patterns of individual rivers is the most effective means of quality control (Marsh 2002).

Visual quality control procedures use versatile hydrograph plotting and manipulation software to enable comparisons between different near-neighbour or analogue flow measurement sites, assessments of catchment rainfall input hyetographs, automatic base flow separation and assessment of time series statistics (Figure 5). For each gauging station key flow statistics (such as highest daily mean, lowest 10-day mean, 5 and 95 percentile flows) are calculated for all newly submitted data and automatic routines compare these against the archive historical record. Similar assessment of catchment water balance and double mass comparisons between time series provide the capability to identify shifts in time-series. A fast-access web-based GIS system allows consideration of topography, areal rainfall gradients and land-use across the catchment under scrutiny, as well as identification of analogue gauging stations and raingauges for time-series comparison. Additionally, users are able to consult station metadata records detailing the history of the site and its hydrometric performance, along with previous quality control logs. The use of specialised hydrometric data processing systems (either in-house or commercially marketed) allows thorough assessments of river flow records to be completed in an efficient and auditable way.

The mix of automated and manual assessment of flow variability, coupled with easy access to contextual metadata, allows the regional representatives to make judgements regarding the quality of hydrometric data submitted to the archive. Particular attention is focused on extreme flows: despite the widespread adoption of mobile boat based ADCPs to improve high flow gauging, the nature of many UK river channels is such that out of bank flow remains a major source of uncertainty in high flow data. A critical assessment of new extreme flows (both high and low) ensures that the best available flow estimates are archived for future analysis. Where potential anomalous flows are identified these are queried with data providers under a SLA procedure using auditable enquiry logs. By following a standardised data assessment and improvement procedure such as these, NHIS are able to safeguard against reduced quality data reaching the national archive.

Integral to the SLA are quantitative assessments of the utility of data provided to the NRFA. An objective scoring mechanism assesses the completeness and timeliness of data submissions to the archive and quantity of data where queries confirm problems in the measurement or processing or flows (Hannaford 2004). The use of six simple data metrics (Table 1) allows monitoring of the performance of data providers, individual gauging station 
or groups of gauging stations. The development of a reporting structure based on regional aggregations of these key performance indicators encourages improvements in underperforming parts of the country and focuses attention on data quality improvements (Table 2). The SLA has been in place in the UK since 2002 and over this period marked advances have been seen in those areas of data quality assessed by the system (Figure 6).

Improvement in the overall national completeness of daily mean flow records (the key river flow dataset archived at a national level in the UK) and percentage of stations providing complete series to the NRFA have been observed over the operational period of the SLA (Figures 6a and 6b). Data completeness is particularly important as a data quality indicator as erroneous or missing data severely impacts on the usability of hydrometric time series. In particular, even short segments of missing data points in gauged daily flow series have considerable implications for the calculation of derived series that are widely used in the analysis of hydrometric data (e.g. regional runoff, 7-day minima). The implications of incomplete data series can be considerable if they occur during flow extremes, impacting on series such as the annual maximum and thus impinge on analysis of changes in the frequency/magnitude of extreme flow. Periods of missing data often result from instrument errors during data capture or data processing problems at high or low flows. It is important to have a complete flow series wherever possible and where backup observed data is not available, the informed use of appropriate techniques to provide estimated flows (flagged as such) is preferable to missing data points. The NRFA has recently carried out an intercomparison of fifteen statistical data infilling techniques with a view to identifying those most suited to the estimation of daily mean flows in the UK (Harvey et al. 2012). Such research informs the development of best practice guidance for data providers.

Through the operation of a controlled data provision, validation and archival process and a combined focus by those maintaining monitoring networks and NHIS to maximise data quality and completeness the utility of national datasets can be improved. Such systems could easily be transferred to help control hydrometric information lifecycles in other part of the world. However, Marsh (2002) highlights the danger of data quality appraisal systems that operate too mechanistically, concentrating on the separate indices of data quality rather than the overall information delivery. To mitigate against such issues the SLA system in the UK is closely connected with other initiatives, such as the dedicated measuring authority liaison and promotion of best practice mentioned above, which aim to improve broader data utility. For example, in assessing data quality a SLA metric counting the number of queries logged by the NRFA allows a quantitative comparison between regions and charts development over time, but the impact of specific queries on the utility of a station's record cannot be captured in a simple index. By linking a region's SLA performance into the Hydrometric Data Audit Framework, the NRFA is able to focus investigations on the causes of repeated year-on-year data queries and review commonly occurring regional hydrometric issues. Where issues cannot be resolved the NRFA works with local hydrometric teams to ensure that metadata records alert the user to any potential data limitations.

\section{Data Synthesis and Analysis}


The primary roles of National Hydrometric Information Services usually focus on the acquisition, management and dissemination of hydrological data. In this way, they act as a key source of empirical observations for subsequent analysis by a broad community of end users. However, NHIS are often also uniquely placed to deliver large scale contemporary, and historical scientific assessments of hydrological data. This is especially true in the active monitoring of the national hydrological situation or the assessment of conditions at times of widespread flood or drought. Since 1988 the NRFA has, in conjunction with the UK National Groundwater Level Archive, operated the National Hydrological Monitoring Programme (NHMP). The NHMP services a wide range of UK users providing input to scientific reports and research projects, as well as informing policy decisions, media briefings, and increasing public understanding of the state of the water environment. The programme provides routine monthly reports which contain statistics and commentary on the current national hydrological situation, including assessments of rainfall, river flow, groundwater and reservoir stocks (Figure 7) (NERC 2013). The inclusion of groundwater and surface water storage observations in such assessments is crucial to fully understanding the national water resources situation and often requires NHIS, monitoring authorities and private sector water supply companies to cooperate and share information in near-real time. The reports are aimed at a wide audience -including government bodies, regulators, academia and the media - and provide a snapshot of the current national situation and its historical context. Such reporting becomes of paramount importance during drought episodes; the monthly summary provides information on the severity and spatial extent of meteorological and hydrological drought conditions and current water resource status as the event develops.

The importance of monitoring programme such as the NHMP, which bring together current hydrometric observations and contextual analysis, is borne out by the number of similar initiatives in other parts of the world, such as the US Drought Monitor (http://droughtmonitor.unl.edu/). In addition to monthly situation reporting the NHMP conducts annual reviews of the hydrological year and reactive analysis of flood or drought episodes, capitalising on long term situation monitoring and analysis to provide scientifically based assessments in the aftermath of notable events. The NHMP has a long history of carrying out such analyses, recent examples being an assessment of the widespread England and Wales flooding in summer 2007 (Marsh and Hannaford 2007) and the flooding in northwest England in November 2009 (Miller et al. 2013).

Globally, concerns about recent hydrological variability are prompting increased scrutiny of hydrological time series and, in particular, assessments of long-term trends in hydrological records. Identification of emerging trends is a fundamentally important use of hydrometric data; observational data on hydrological change is needed to provide "ground-truth" against which scenario-based climate models can be verified. NHIS are often best placed to conduct or inform scientific analysis of river flow change at a national or international level and act as a source of advice on data use and guidance on interpretation of flows patterns. In the UK, river flow data from the national archive, often focusing on the Benchmark network, have been used extensively by the NRFA and others in the assessment of trends over the instrumental record (e.g. Dixon et al. 2006, Hannaford and Marsh 2006, 2008, Quinn 2010) and in studies focusing on relationships between streamflow and climate drivers such as 
atmospheric teleconnections (e.g. Laize et al. 2010, Lavers et al. 2010). Recently, Marsh and Harvey (2012) examined trends in the flood record for the River Thames at Kingston (1883 present), the longest available continuous record on the NRFA. However, this record is a rarity, and only a handful of records extend back before 1930 (Figure 1b). With their longterm perspective, NHIS have a role to play in highlighting the paramount importance of long records such as this one, in ensuring such series are preserved and continued into the future (particularly where they may appear to be of little contemporary operational value) and, moreover, in encouraging the rescue and digitisation of long analogue records which may help improve our characterisation of pre-instrumental hydro-climatic variability. For example, the NRFA helped recover the earliest extant UK flow data (from 1841) for a springflow site in southern England, which has provided a rare glimpse into hydrological conditions of the mid- to -late nineteenth century (Bayliss et al. 2004).

\section{Data Dissemination}

One of the primary functions of a National Hydrometric Information Service is to provide comprehensive, coherent access to information at a scale and resolution appropriate for a wide range of end-users. At global, regional and local scales efforts to meet complex environmental challenges are demanding ever increasing access to interoperable observations of freshwater systems from a wider and more diverse community of users. The NRFA operates a policy of open-access to its data for all users. Research customers make up around $60 \%$ of the NRFA user community with the remaining audience spanning the government, commercial, and education and media sectors (Figure 8).

Meeting users changing requirements necessitates almost constant adaptation and updating of data management practices by NHIS. For large parts of the $20^{\text {th }}$ Century the primary data dissemination route for national hydrometric data was via annual hard-copy publications of data tables (e.g. UK Surface Water Yearbooks produced between 1935 and 1995 - e.g. NERC 1996). However, the last 15 years has seen a shift towards more dynamic web-based data dissemination to meet the requirement for shorter lag-time between observation and data publication and ease of data reuse.

A key dissemination route for UK river flow data and associated metadata is via an online web-portal which provides users with dynamic access to a wide range of information to allow selection of gauging stations for analysis and, for a sub-set of stations (c.400, around a third of the NRFA) which have been subjected to a higher level of quality control over the full period-of-record, access to the full flow data record for download (http://www.ceh.ac.uk/data/nrfa). A map-based feature allows users to find data by geographic location, or by searches based on gauging station, catchment or time series metadata, for example identifying stations with a mean flow greater than $50 \mathrm{~m}^{3} / \mathrm{s}$, or where the catchment land cover is over 50\% forest. Once locations of interest have been selected, web-pages for each gauging station provide NRFA metadata allowing users to assess the quality and extent of the flow record prior to downloading (Figure 9).

While web-based dissemination is now the standard method of onward data transfer for the NRFA, this facility is complemented by a dedicated manual enquiry and data retrieval service 
(Figure 4). Dealing with around 450 enquiries a year the service is able to provide users with advice on data holdings or specific gauging stations as well as supplying customised data retrievals. Considerable value is added to the service if NHIS are able to provide data users with access to additional datasets that can help interpret the baseline hydrometric records. The availability of catchment averaged rainfall series allows users to interpret catchment inputs while spatial datasets can provide an understanding of the nature of the catchments for example: land-use, hydro-geology, topography and drainage networks. Spatial data pages on the NRFA website provide maps and statistics on the range of catchment descriptors available.

A key stewardship role for NHIS is the maintenance and dissemination of user guidance information. Along with basic gauging station discovery metadata (e.g. geographical location, station type, catchment area), contextual information about the station hydrometry and flow record provide the user with vital guidance which should be considered during analysis and interpretation. As data storage capabilities increase and information management systems allow ever more detailed metadata collection, the potential quantity of contextual information available to the end-user has burgeoned. Through careful quality control and application of informed judgement, NHIS are able to produce composite user guidance summaries that draw users' attention to key information and record caveats (e.g. marked artificial influences on the flow regime, high levels of uncertainty regarding specific flood event accuracy, major changes in hydrometric setup). Web-based dissemination of user-guidance and discovery metadata can usefully be complemented by publication of registers of hydrometric stations (e.g. Marsh and Hannaford 2008).

At national and international levels the application of large-scale multi-site analysis techniques to river flow records is growing as computing power and data access improves. Such projects are vital to meeting the global water challenges of the $21^{\text {st }}$ Century. However, this issue represents a key problem for NHIS in balancing ease of access to data with a promotion of responsible data use (where the data context and monitoring limitations are considered). Data management practices must facilitate large-scale data analysis and allow widespread data dissemination while maintaining end user access too important contextual hydrological information. Technological data dissemination solutions and international metadata standards should allow NHIS to continue to exercise important data stewardship and promote sensible data use. Scientific users can, through NHIS, play a key role in improving hydrometric data, providing feedback highlighting important issues in relation to records, helping establish network requirements and adding to a centralised knowledge base regarding national data. Through embracing feedback from the end-user community the overall information delivery of a system can be improved.

One increasingly important role of NHIS is the servicing of national obligations in relation to national and international data exchange and statistical reporting. In systems such as the UK, where responsibility for hydrometric monitoring is distributed amongst several organisations, central NHIS are able to draw on data from across the country to provide national scale estimates of water resources. Such statistics are not only vital for long-term policy development but are increasingly shared internationally, for example through the OECD and 
European Commission (European Union 2010). The development of international data sharing initiatives such as the UNESCO-IHP Flow Regimes from International Experimental and Network Data (FRIEND) Programme's European Water Archive (http://www.eurofriend.de/) and the WMO Global Runoff Data Centre (http://grdc.bafg.de) facilitate regional and global use of hydrometric information. NHIS are central to the success of such systems, providing reliable access to and guidance on national data contributions. The NRFA regularly provides data updates to such initiatives, enabling global users to access recent flow records and providing associated metadata which are vital to ensuring that the data stored in largescale depositories is fit for purpose.

\section{CONCLUSIONS}

The Third World Water Development Report highlighted the importance of reliable hydrological data in meeting the world's water resource management needs, stressing the current global data inadequacies and the need to resolve current barriers to data sharing and access (Grabs 2009). Where currently established, National Hydrometric Information Services, play a key role in the delivery of hydrometric information to scientists and water practitioners. Recognition of the need to strengthen national capabilities in hydrometric information was an important output from the $5^{\text {th }}$ World Water Forum (World Water Council 2009). Support is needed to improve national hydrometric data management and dissemination as these are crucial to the success of state-scale water management and also underpin international initiatives to combat global water problems.

This paper has discussed the management and delivery of hydrometric information through the use of a data lifecycle approach, in particular emphasising the importance of maintaining feedback routes between data users and those responsible for data sensing and processing. While internationally networks may vary with respect to organisation setups, gauging methods, data management and data dissemination policies, useful synergies can be developed in all stages of the hydrometric information lifecycle to improve the overall utility of the information output. Models and frameworks outlined in this paper could be usefully adapted for application to other monitoring networks.

Freshwater management decisions and policies should be based upon quantitative knowledge of the hydrological system. The importance of long term monitoring and central contribution of data collectors should be recognised at local, national and international scales. As both the demand for and complexity of hydrometric data increases, the key principles of strategic network design, systematic data quality control, responsible data stewardship and effective information dissemination should be promoted throughout hydrometric observation networks. Hydrometric information systems should be designed such that the utility of data to end-users at all levels is a central consideration.

National and international hydrometric information services are critical to meeting global water management needs. Observational frameworks should be reviewed at all levels to ensure the fitness for purpose of river flow information available to users. Data management systems should be optimised to ensure that maximum benefits are achieved from those resources invested in hydrometric monitoring. In the light of ever increasing global water 
management challenges, the widespread decline of hydrometric network and continued barriers to data sharing, there is a pressing need to maximise the utility of national hydrological databases and the strategic capabilities of monitoring networks.

Acknowledgements The authors acknowledge the ongoing collaboration of the Environment Agency, Scottish Environmental Protection Agency and Northern Ireland Rivers Agency in providing data to the UK National River Flow Archive. The work of the UK Surface and Ground Water Archives Committee is also gratefully acknowledged.

\section{REFERENCES}

Bayliss, A., Norris, J. and Marsh, T.J., 2004. The Wendover Springs record: An insight into the past and a benchmark for the future. Weather, 59 (10), 267-271.

Bradford, R. B. and Marsh, T.J., 2003. Defining a network of benchmark catchments for the UK. Proceedings of The Institution of Civil Engineers -Water and Maritime Engineering, 156 (2), 109-116.

BoM, 2010. Improving Water Information Program - Progress Report 2007-2010. Melbourne: Australian Government Bureau of Meteorology.

Burn, D.H., Hannaford, J., Hodgkins, G.A., Whitfield, P.H., Thorne, R. and Marsh,T.J., 2012. Hydrologic Reference Networks II - Using Reference Hydrologic Networks to assess climate driven change. Hydrological Sciences Journal, 57 (8), 1-15. doi:10.1080/02626667.2012.728705.

Davis, R., Grew, R., Zaidman, M. and Garrett, K., 2010. Evaluating the benefits of the hydrometric network in England and Wales. In: C. Kirby, ed. Role of hydrology in managing consequences of a changing global environment, Proceeding of the BHS Third International Symposium, July 2010. Newcastle, UK: British Hydrological Society, 787-793.

Dixon, H., Lawler, D.M. and Shamseldin, A.Y., 2006. Streamflow trends in western Britain. Geophysical Research Letters, 33 (19), doi: 10.1029/2006GL027325.

European Union, 2010. Europe in figures: Eurostat yearbook 2010. Eurostat Statistical Books. Luxembourg: European Union.

Franks, S., Sivapalan, M., Takeuchi, K. and Tachikawa, Y., eds., 2005. Prediction in Ungauged Basins: International Perspective on the state of the art and pathways forward. IAHS Publication 301. Wallingford: IAHS Press.

Grabs, W., 2009. Bridging the observational gap. The United Nations World Water Development Report 3: Water in a Changing World, World Water Assessment Programme, Paris: UNESCO Publishing/Earthscan, 226-236.

Hannaford, J., 2004. Development of a strategic data management system for a national hydrological database: The UK National River Flow Archive. In: S.Y. Liong, K.K. Phoon and V. Babovic, eds. Proceeding of 6th International Conference on Hydroinformatics, Singapore, 21-24 June 2004. Singapore: World Scientific Publishing, 637-644. 
Hannaford, J. \& Marsh, T.J., 2006. An assessment of trends in UK runoff and low flows using a network of undisturbed catchments. International Journal of Climatology, 26 (9), 1237-1253.

Hannaford, J. and Marsh, T.J., 2008. High-flow and flood trends in a network of undisturbed catchments in the UK. International Journal of Climatology, 28 (10), 1325-1338.

Hannaford, J., Holmes, M.G.R., Laizé, C.L.R., Marsh, T.J. and Young, A.R., in press. Optimising hydrometric networks for regionalisation: a new methodology and its application to England and Wales. Hydrology Research, doi:10.2166/nh.2012.115.

Hannah, D.M., Demuth, S. van Lanen, H.A.V., Looser, U., Prudhomme, C., Rees, G., Stahl K. and Tallaksen, L., 2010. Large-scale river flow archives: importance, current status and future needs. Hydrological Processes, 25 (7), 1191-1200. 10.1002/hyp.7794

Harvey, C.L., Dixon, H. and Hannaford, J., 2012. An appraisal of the performance of data infilling methods for application to daily mean river flow records in the UK. Hydrology Research, 43 (5), 618-636, doi:10.2166/nh.2012.110.

Harvey, K.D., Pilon, P.J. and Yuzyk, T.R., 1999. Canada's Reference Hydrometric Basin Network (RHBN). Proceedings of the CWRA 51st Annual Conference, Nova Scotia, June 1999.

Herschy, R.W., 2009. Streamflow Measurement. London: Taylor \& Francis.

Institute of Hydrology, 1999. Flood Estimation Handbook, 5 Volumes. Wallingford: Institute of Hydrology.

Laizé, C.L.R., 2004. Integration of spatial datasets to support the review of hydrometric networks and the identification of representative catchments. Hydrology and Earth System Science, 8 (6), 1103-1117.

Laizé, C.L.R., Marsh, T.J. and Morris, D.G., 2008. Catchment descriptors to optimise hydrometric networks. Proceedings of the Institution of Civil Engineers-Water Management, 161 (3), 117-125.

Laizé, C.L.R. and Hannah D.M., 2010. Modification of climate-river flow associations by basin properties. Journal of Hydrology, 389 (1-2), 186-204.

Lavers, D., Prudhomme, C. and Hannah, D.M., 2010. Large-scale climate, precipitation and British river flows: Identifying hydroclimatological connections and dynamics. Journal of Hydrology, 395 (3-4), 242-255.

Marsh, T.J., 2002. Capitalising on river flow data to meet changing national needs - a UK perspective. Flow Measurement and Instrumentation, 13 (5-6), 291-298.

Marsh, T.J. and Hannaford, J., 2007. The summer 2007 floods in England and Wales - a hydrologcial appraisal. Wallingford: NERC Centre for Ecology \& Hydrology.

Marsh, T.J. and Hannaford, J., eds., 2008. UK Hydrometric Register. Wallingford: NERC Centre for Ecology \& Hydrology. 
Marsh, T.J. and Harvey, C.L., 2012. The Thames flood series: a lack of trend in flood magnitude and a decline in maximum levels. Hydrology Research, 43 (3), 203-214. doi:10.2166/nh.2012.054

Miller, J.D., Kjeldsen, T.R., Hannaford, J. and Morris, D.G., 2013. A hydrological assessment of the November 2009 floods in Cumbria, UK. Hydrology Research, 44 (1) 180-197. doi:10.2166/nh.2012.076.

Mishra, A.K. and Coulibaly, P., 2009. Development in hydrometric network design: A review, Reviews of Geophysics, 47 (2), doi: 10.1029/2007RG000243.

Nelson, B., 2009. Data Sharing: Empty Archives. Nature, 461, 160-163, doi: 10.1038/461160a.

NERC, 1996. Hydrological Data United Kingdom: 1995 Yearbook. National Water Archive, Wallingford: NERC Centre for Ecology \& Hydrology/British Geological Survey.

NERC, 2013. Hydrological Summary for the United Kingdom. National Hydrological Monitoring Programme, Monthly Pub., Wallingford: NERC Centre for Ecology \& Hydrology/British Geological Survey.

Norris, J.M., 2009. National Streamflow Information Program, Implementation Status Report. U.S. Geological Survey Fact Sheet 2009-3020. Reston, VA: USGS.

Quinn, N., 2010. Are trends in flashiness evident in natural catchments in the United Kingdom? In: C. Kirby, ed. Role of hydrology in managing consequences of a changing global environment, Proceeding of the BHS Third International Symposium, July 2010. Newcastle, UK: British Hydrological Society, 150-160.

Rodda, J.C., 1998. Hydrological networks need improving! In: H. Zebidi, ed., Water: a looming crisis? - International conference on world water resources at the beginning of the 21st century. Technical Documents in Hydrology - No. 18, Paris: UNESCO, 91-102.

Slack, J.R. and Landwehr, J.M., 1992. Hydro-Climatic Data Network (HCDN): A U.S. Geological Survey streamflow data set for the United States for the study of climate variations, 1874-1988. USGS Open-File Report 92-129. Reston, VA: USGS.

Stahl, K., Hisdal, H., Hannaford, J., Tallaksen, L.M., van Lanen, H.A.J., Sauquet, E., Demuth, S., Fendekova, M. and Jodar, J., 2010. Streamflow trends in Europe: evidence from a dataset of near-natural catchments. Hydrology and Earth System Sciences, 14 (12), 2367-2382.

Viglione, A., Borga, M., Balabanis, P. and Blöschl, G., 2010. Barriers to the exchange of hydrometeorological data in Europe: Results from a survey and implications for data policy. Journal of Hydrology, 394 (1-2), 63-77. doi:10.1016/j.jhydrol.2010.03.023.

Whitfield, P.H., Burn, D.H., Hannaford, J., Higgins, H., Hodgkins, G.A., Marsh, T.J. and Looser, U., 2012. Hydrologic Reference Networks I: The Status of National Reference Hydrologic Networks for Detecting Trends and Future Directions. Hydrological Sciences Journal, 57 (8), 1-18. doi:10.1080/02626667.2012.728706. 
WMO (2006) Guidelines on the Role, Operation and Management of National Hydrological Services, WMO-No. 1003, World Meteorological Organisation, Geneva, 83 pp.

WMO, 2008. Guide to hydrological practices: Volume 1, WMO-No.168, 6th ed., Geneva: World Meteorological Organisation.

World Water Council, 2009. Global Water Framework - Outcomes of the 5th World Water Forum, Istanbul 2009. World Water Council / Secretariat of the 5th World Water Forum / Turkish Ministry of Foreign Affairs. 


\section{TABLES}

Table 1 Service Level Agreement metrics used to appraise data provided to the NRFA. Scores are applied to individual gauging stations and then aggregate scores calculated for regions or authorities.

\begin{tabular}{|c|c|c|}
\hline SLA Metric & Description & Rationale \\
\hline Data Timeliness & $\begin{array}{l}\text { Score based on date of arrival at the } \\
\text { NRFA of the annual data submission } \\
\text { from the regional hydrometric } \\
\text { measuring authority. }\end{array}$ & $\begin{array}{l}\text { Assessment of adherence to the annual } \\
\text { data provision timetable designed to } \\
\text { encourage prompt data submission to } \\
\text { the national archive enabling users to } \\
\text { access contemporary data. }\end{array}$ \\
\hline $\begin{array}{l}\text { Daily Mean Flow } \\
\text { Completeness }\end{array}$ & $\begin{array}{l}\text { Number of missing daily mean flows } \\
\text { relative to number of expected daily } \\
\text { flows for an individual station. }\end{array}$ & $\begin{array}{l}\text { Measure of the completeness of a time- } \\
\text { series designed to encourage the use of } \\
\text { data capture backup systems and, where } \\
\text { appropriate, data infilling to minimise } \\
\text { unnecessary gaps in records. }\end{array}$ \\
\hline $\begin{array}{l}\text { Station } \\
\text { Completeness }\end{array}$ & $\begin{array}{l}\text { For any one region/organisation, the } \\
\text { percentage of stations with a } \\
\text { complete year of data relative to the } \\
\text { total number of stations. }\end{array}$ & $\begin{array}{l}\text { Assessment of the extent of data } \\
\text { completeness issues across the regional } \\
\text { network. }\end{array}$ \\
\hline $\begin{array}{l}\text { Daily Mean Flow } \\
\text { Queries }\end{array}$ & $\begin{array}{l}\text { Score based on number of daily flow } \\
\text { values for which the NRFA identifies } \\
\text { data queries during validation } \\
\text { processes. The score is calculated for } \\
\text { queries where the data is found to be } \\
\text { incorrect due to a hydrometric or data } \\
\text { processing error. }\end{array}$ & $\begin{array}{l}\text { An assessment of data quality based on } \\
\text { the secondary data validation conducted } \\
\text { by the NRFA. }\end{array}$ \\
\hline Station Queries & $\begin{array}{l}\text { For any one region, the percentage of } \\
\text { stations where no flow data is queried } \\
\text { by the NRFA, relative to the total } \\
\text { number of stations. }\end{array}$ & $\begin{array}{l}\text { Assessment for the extent of data } \\
\text { quality issues across the regional } \\
\text { network. }\end{array}$ \\
\hline Query timeliness & $\begin{array}{l}\text { Score based on timeliness of } \\
\text { measuring authority response to } \\
\text { NRFA data queries. }\end{array}$ & $\begin{array}{l}\text { Assessment of the adherence to the } \\
\text { agreed time window for response to } \\
\text { NRFA data queries ensures issues are } \\
\text { resolved. }\end{array}$ \\
\hline
\end{tabular}


Table 2 Service Level Agreement scores for regional river flow data provision to the NRFA during 2010. Note: regions vary in geographical size and therefore the number of gauging stations covered by the SLA varies throughout the country. A score formatted in bold represent a strong performance, while italicised scores represent areas where improvements should be targeted.

\begin{tabular}{|c|c|c|c|c|c|c|c|c|}
\hline $\begin{array}{c}\text { Hydrometric } \\
\text { Measuring } \\
\text { Authority }\end{array}$ & Region & $\begin{array}{c}\text { Number } \\
\text { of SLA } \\
\text { Stations }\end{array}$ & $\begin{array}{c}\text { Data } \\
\text { Timeliness } \\
\text { (/10) }\end{array}$ & $\begin{array}{c}\text { Overall Daily } \\
\text { Mean Flow } \\
\text { Completeness } \\
(/ 10)\end{array}$ & $\begin{array}{c}\text { Complete } \\
\text { Stations } \\
\text { (\%) }\end{array}$ & $\begin{array}{c}\text { Overall } \\
\text { Daily } \\
\text { Mean } \\
\text { Flow } \\
\text { Queries } \\
(/ 10)\end{array}$ & $\begin{array}{c}\text { Non- } \\
\text { Queried } \\
\text { Stations } \\
(\%)\end{array}$ & $\begin{array}{c}\text { Query } \\
\text { Timeliness } \\
\text { (/10) }\end{array}$ \\
\hline \multirow{8}{*}{ A } & A1 & 62 & 10.00 & 9.78 & 93.44 & 10.00 & 98.33 & 10.00 \\
\hline & A2 & 71 & 8.48 & 10.00 & 97.18 & 9.99 & 98.59 & 10.00 \\
\hline & A3 & 71 & 10.00 & 9.99 & 98.59 & 10.00 & 100.00 & 10.00 \\
\hline & A4 & 69 & 10.00 & 10.00 & 100.00 & 9.98 & 98.55 & 10.00 \\
\hline & A5 & 50 & 4.98 & 9.44 & 87.76 & 9.89 & 91.49 & 4.21 \\
\hline & A6 & 65 & 9.88 & 10.00 & 93.75 & 9.98 & 98.44 & 10.00 \\
\hline & A7 & 65 & 9.85 & 9.97 & 70.97 & 9.98 & 98.39 & 9.50 \\
\hline & A8 & 48 & 10.00 & 9.79 & 95.74 & 9.84 & 95.74 & 7.14 \\
\hline \multirow{4}{*}{ B } & B1 & 25 & 10.00 & 10.00 & 96.00 & 10.00 & 96.00 & 10.00 \\
\hline & B2 & 48 & 8.43 & 9.55 & 91.67 & 9.97 & 93.48 & 8.25 \\
\hline & B3 & 39 & 9.86 & 9.45 & 76.92 & 9.85 & 72.97 & 0.00 \\
\hline & B4 & 56 & 9.97 & 9.82 & 92.86 & 9.98 & 90.91 & 10.00 \\
\hline C & & 42 & 10.00 & 10.00 & 100.00 & 9.62 & 83.33 & 7.14 \\
\hline \multicolumn{2}{|c|}{$\begin{array}{l}\text { Average Score Across } \\
\text { UK SLA Network }\end{array}$} & 715 & 9.36 & 9.85 & 92.07 & 9.94 & 94.70 & 6.58 \\
\hline
\end{tabular}




\section{FIGURES}

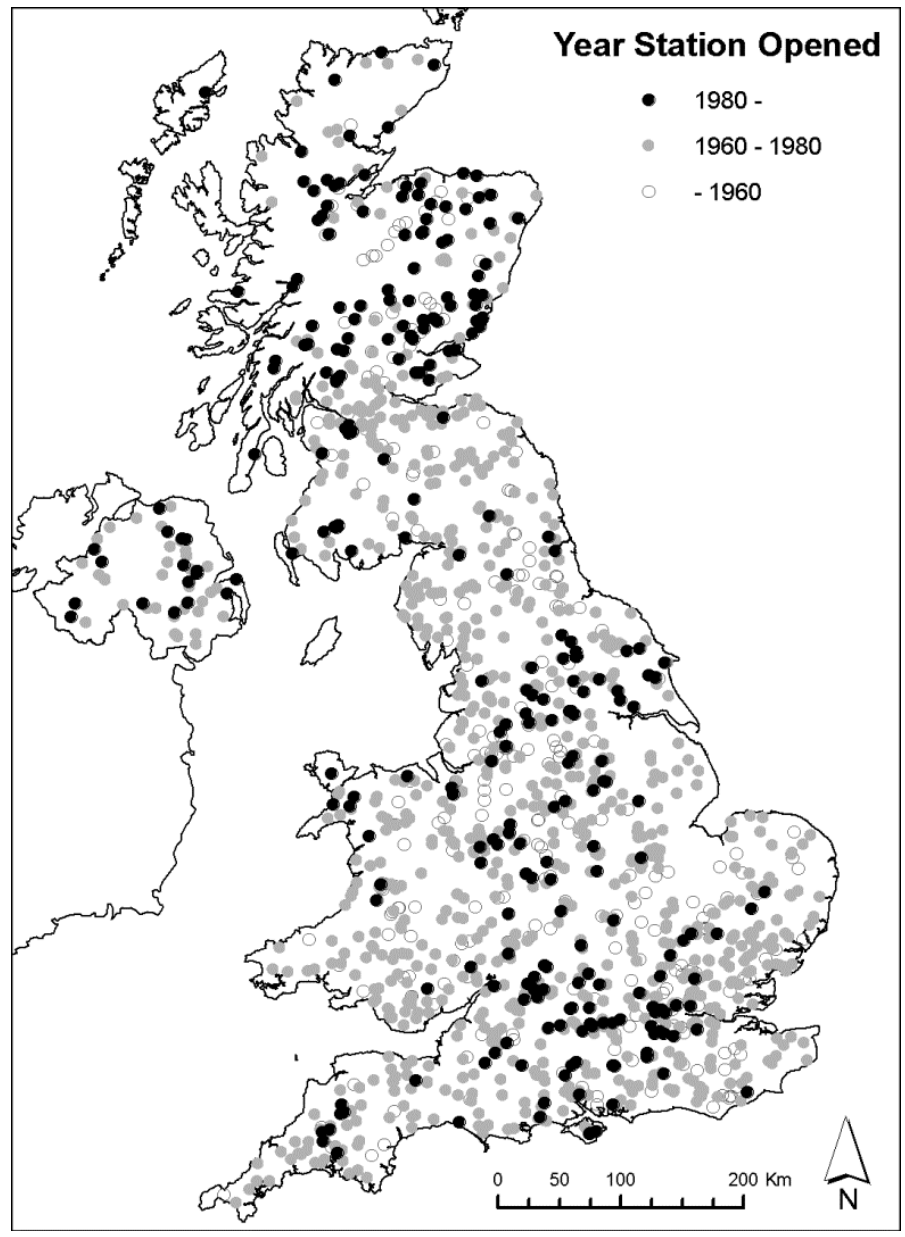

Figure 1a The UK Gauging Station Network - stations shaded by the period in which they were opened.

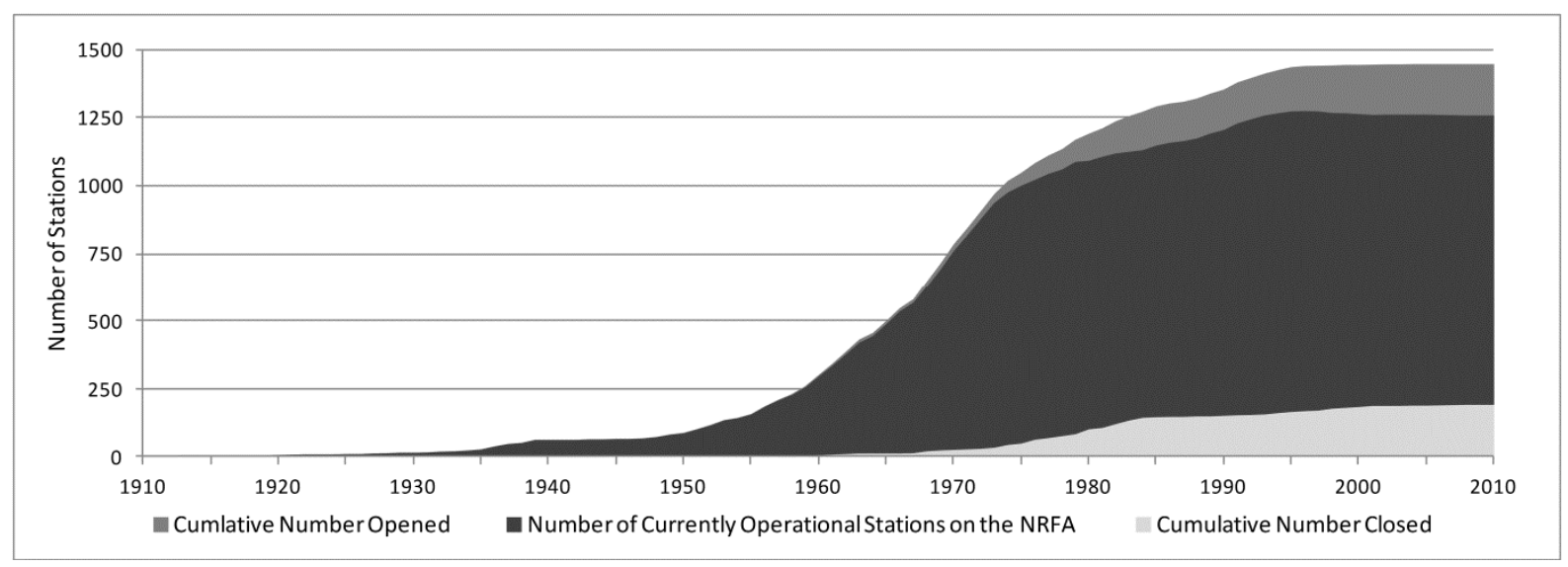

Figure 1b Evolution of the UK Gauging Station Network - shown by the cumulative number of a) opened b) closed and c) currently operational gauging stations held on the NRFA. 


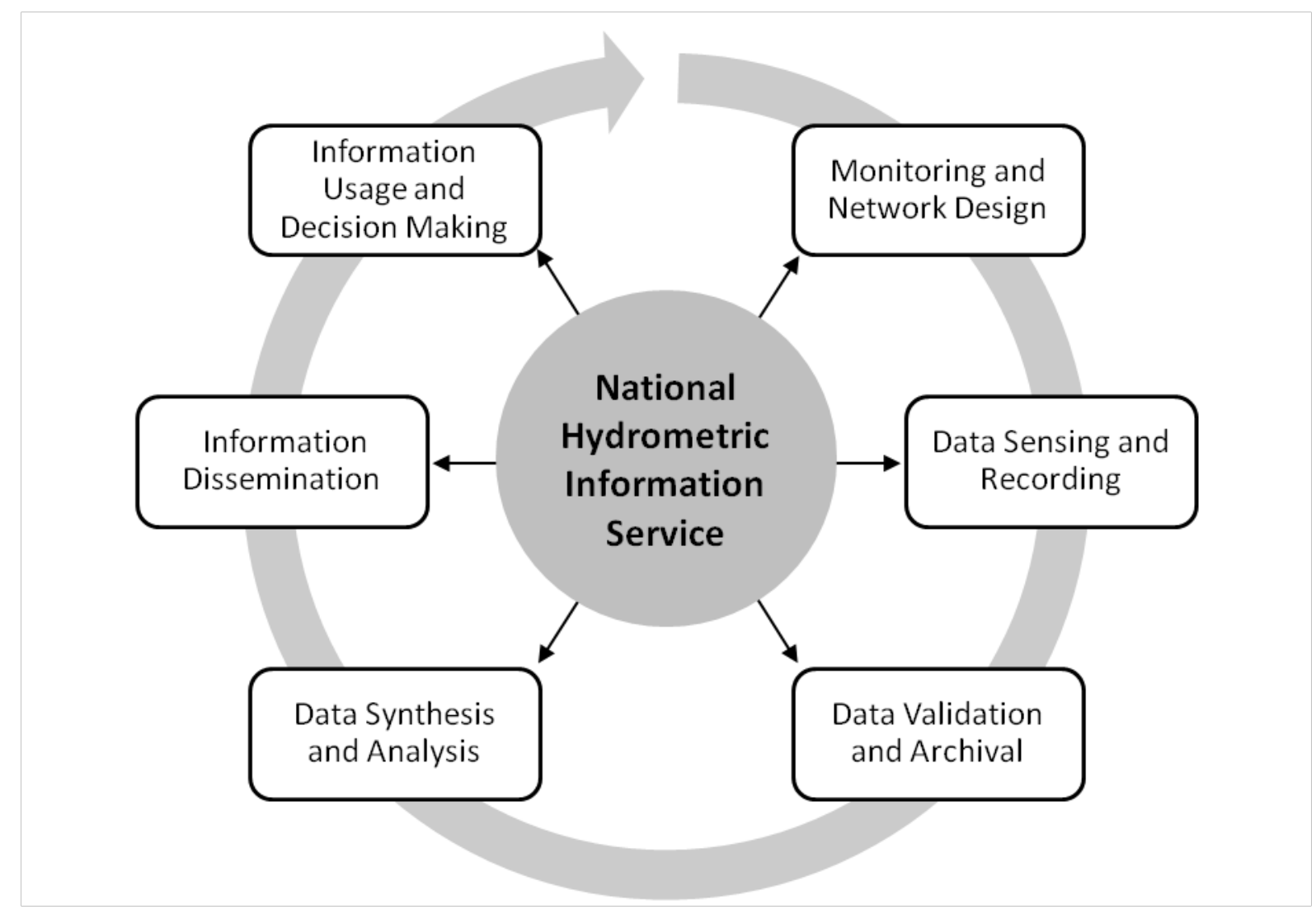

Figure 2 Hydrometric information lifecycle (after: Marsh 2002)
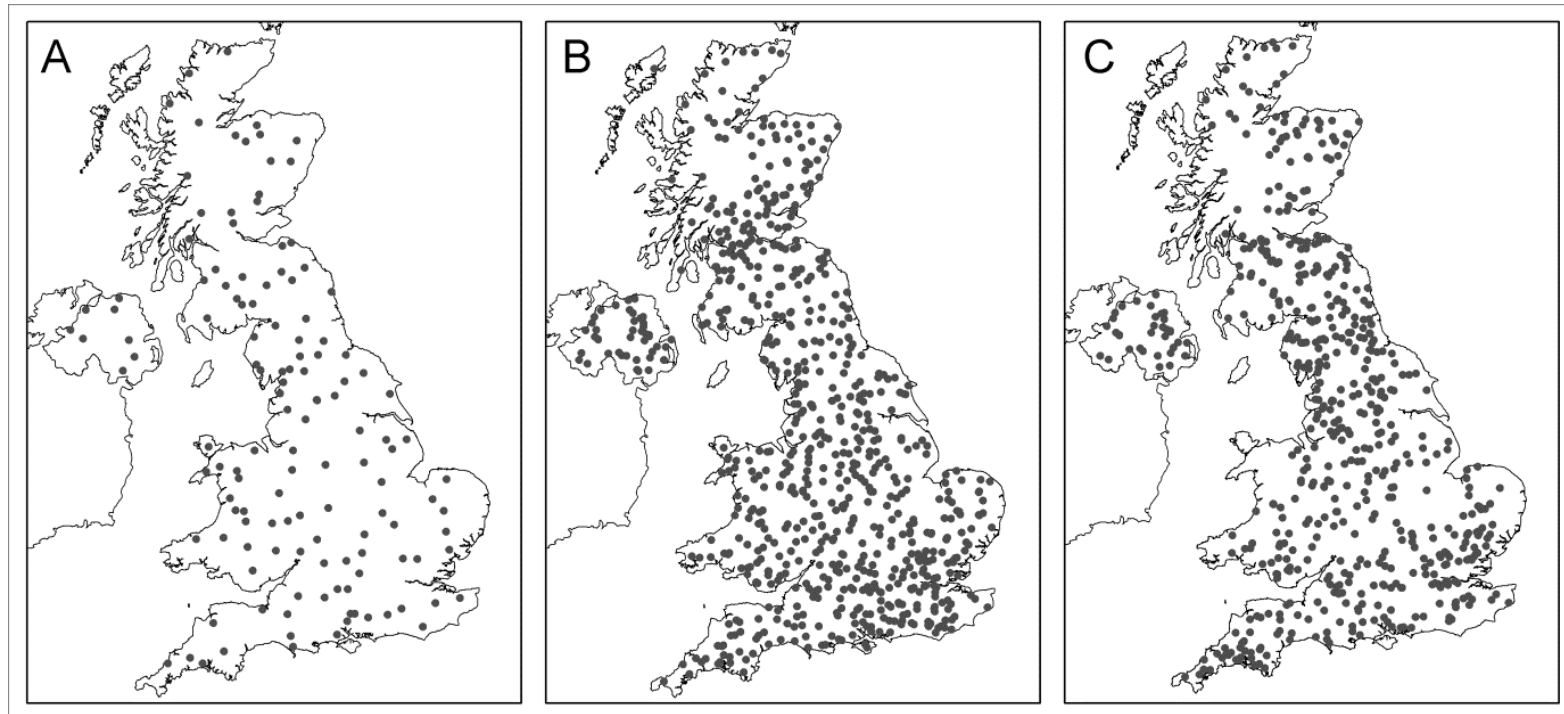

Figure 3 Designated sub-networks of the UK gauging station network: (a) Benchmark network (b) NRFA Service Level Agreement network (c) HiFlows-UK Pooling network. 


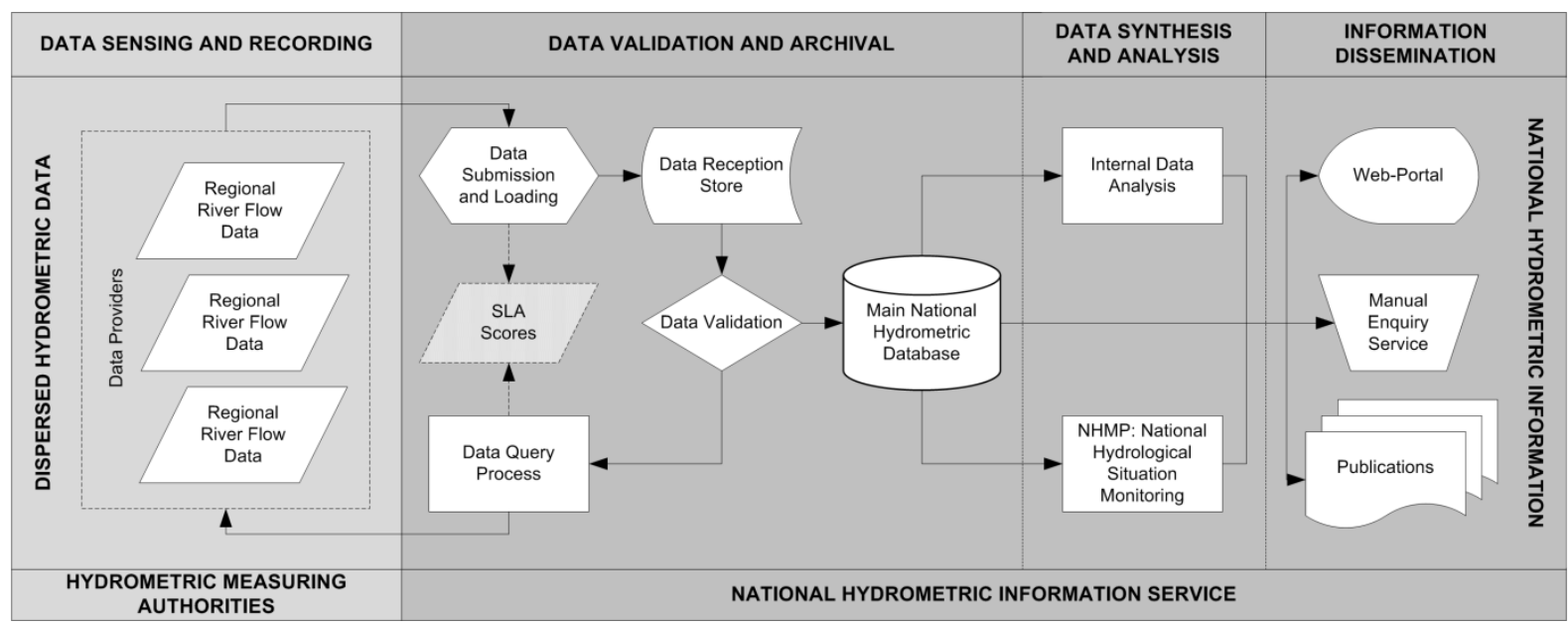

Figure 4 Schematic representation of NRFA data validation, analysis and dissemination procedures

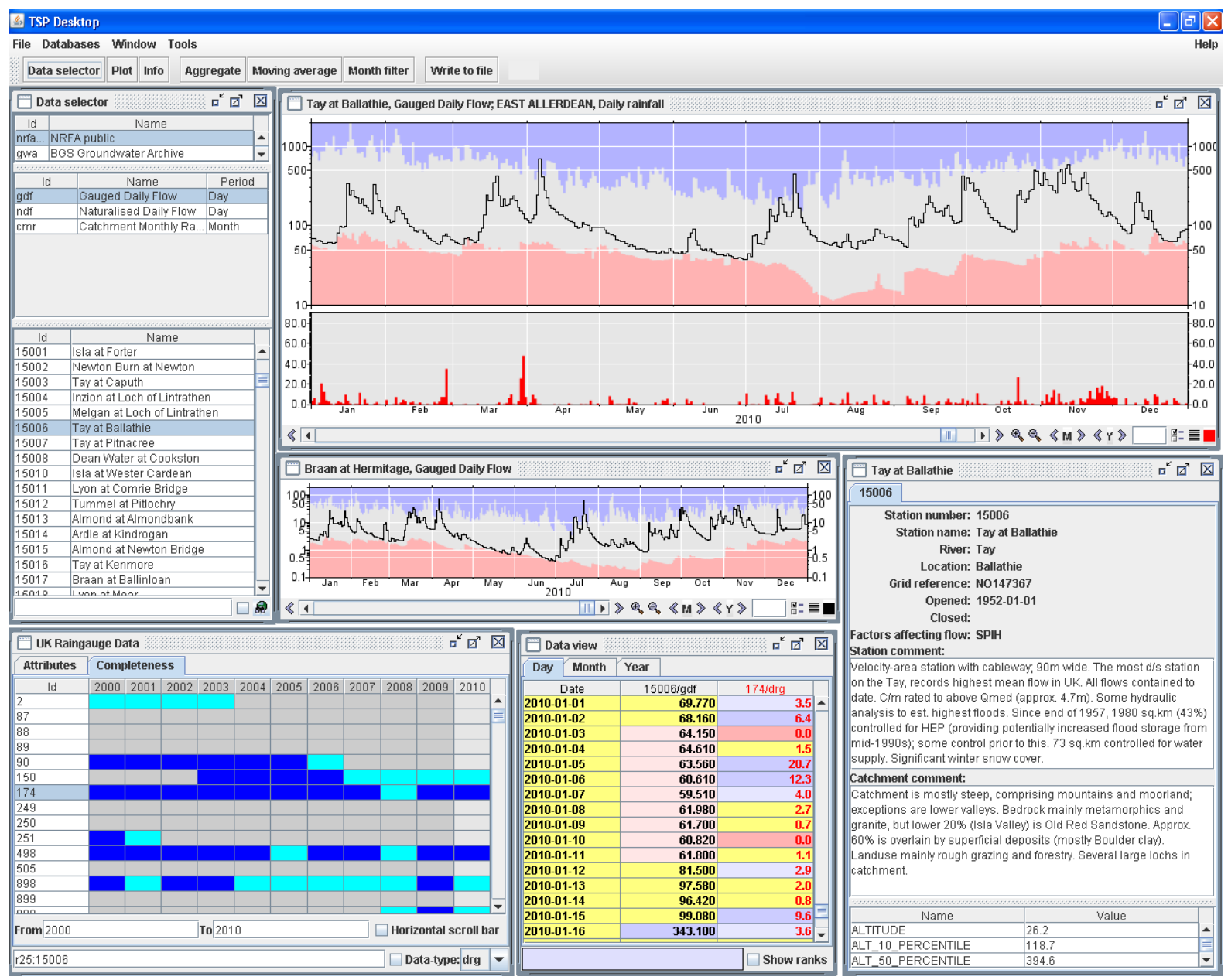

Figure 5 Screenshot from NRFA's in-house hydrograph plotting and manipulation software 
A
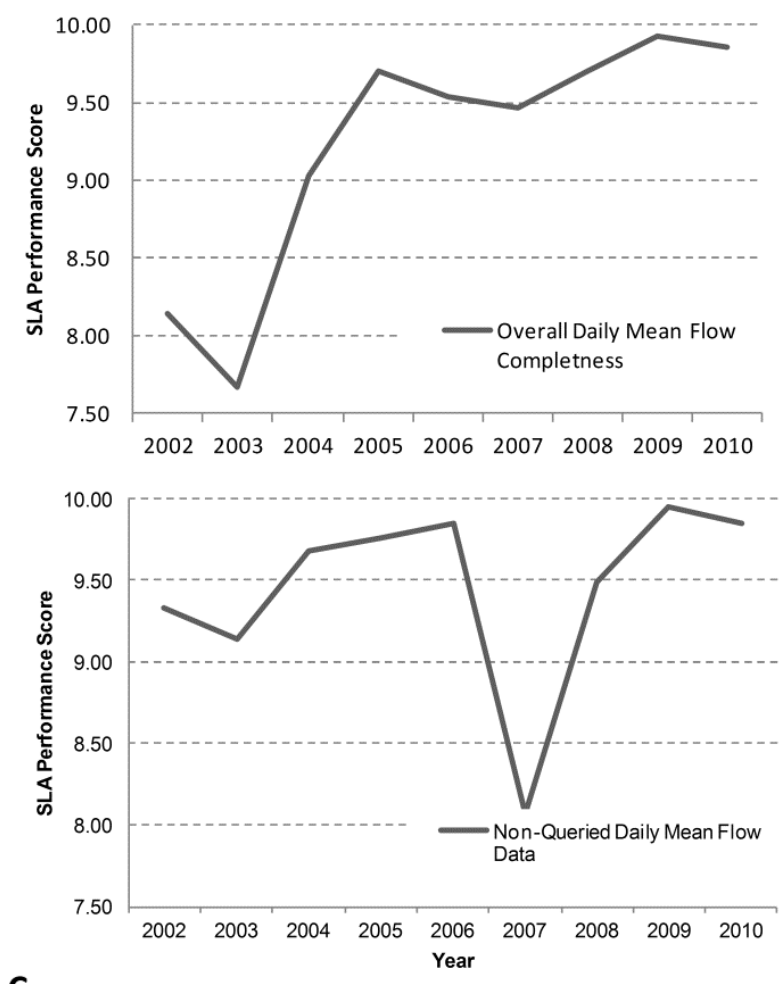
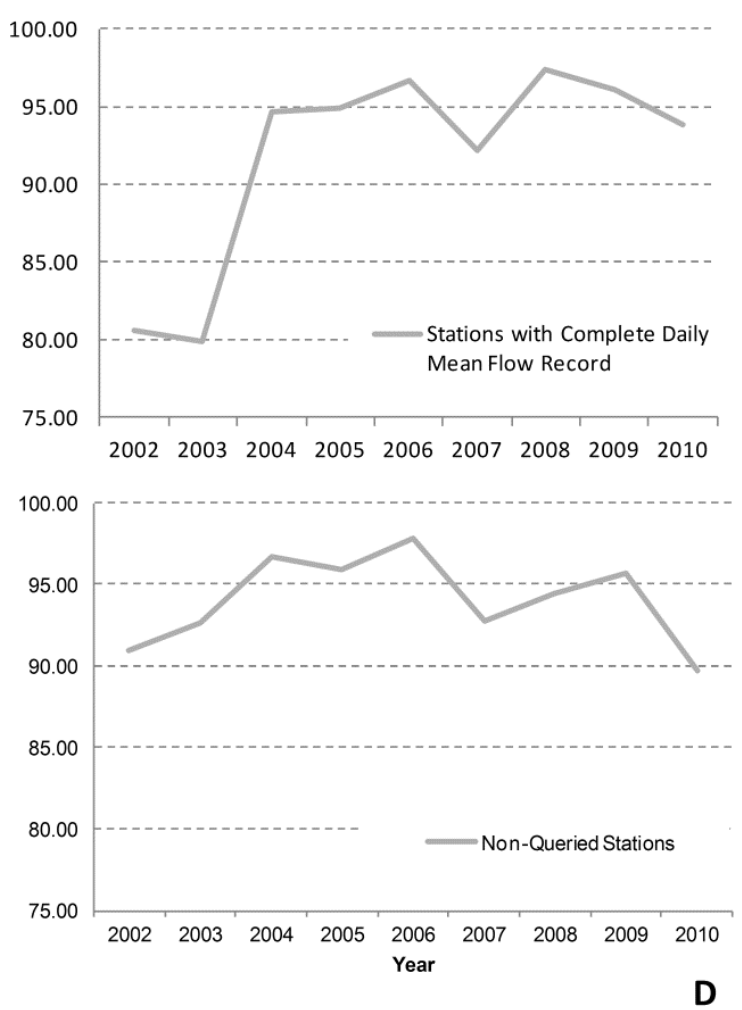

Figure 6 Service Level Agreement scores for annual river flow data provision to the NRFA 2002-2010 


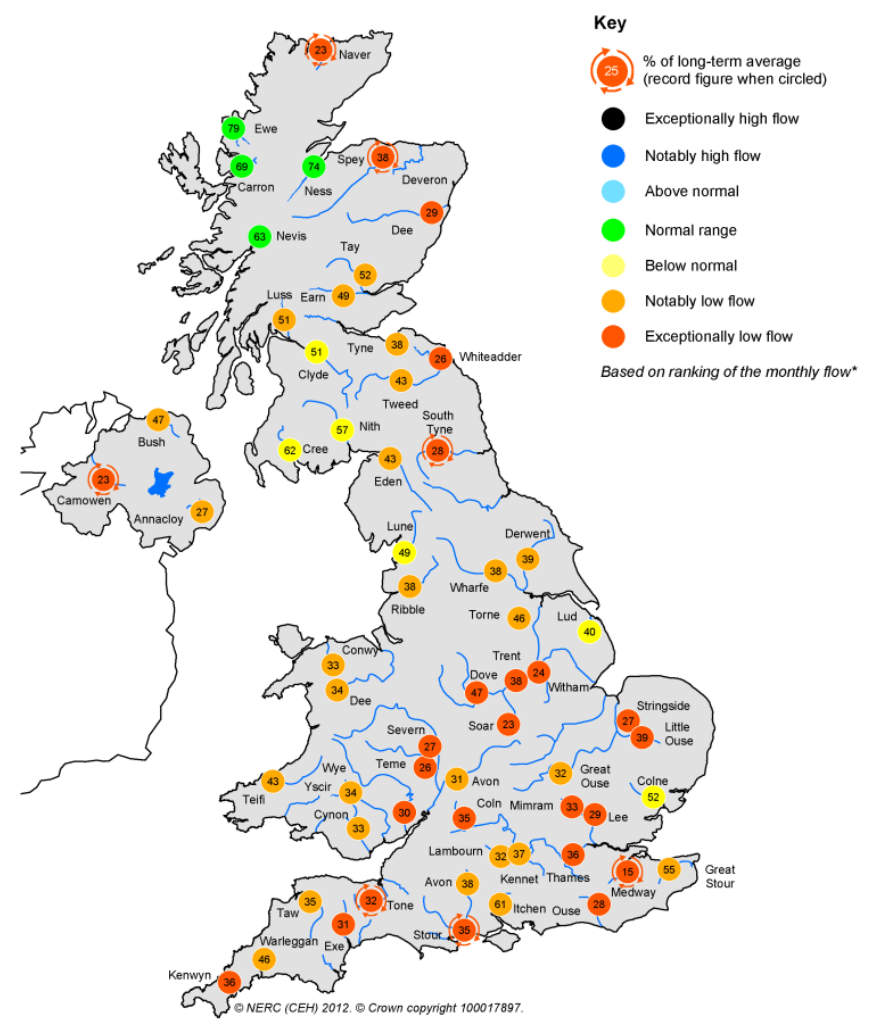

Figure 7 Example hydrological situation reporting published under the National Hydrological Monitoring Programme: UK river flows in March 2012 during a period of drought conditions across the southeast of the country.

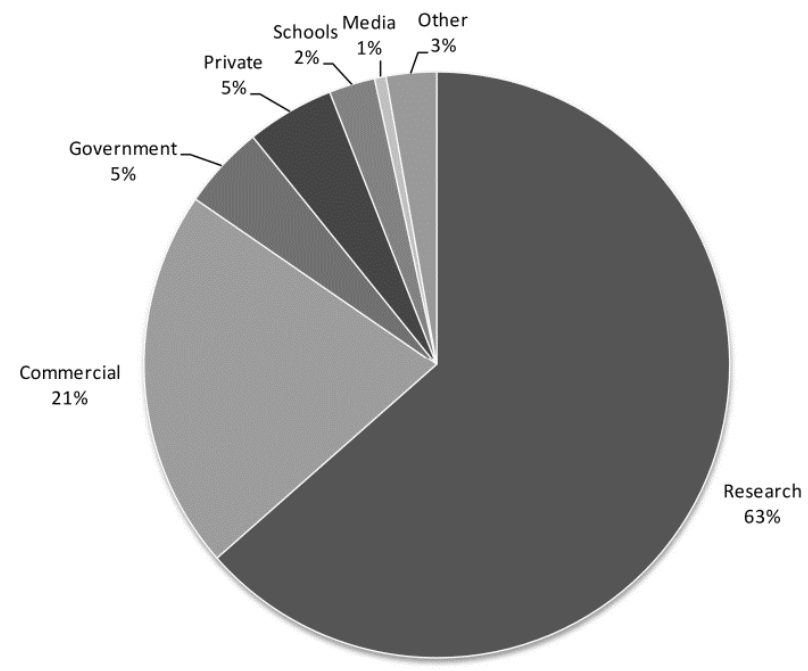

Figure 8 Enquiries and data retrievals handled by the NRFA helpdesk by sector between 2008 and 2011. 


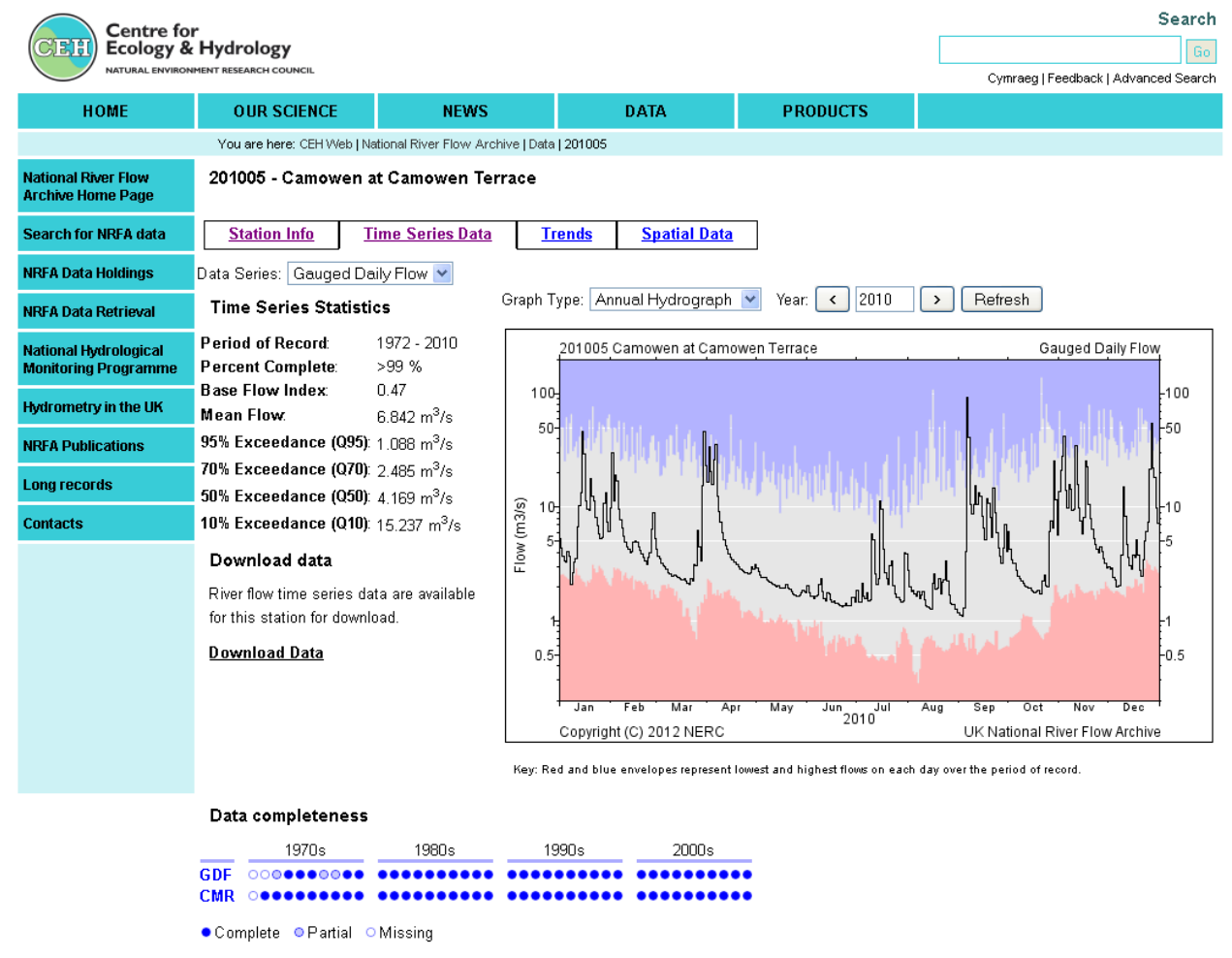

Figure 9 Example time-series exploration pages available via the NRFA website. 